\title{
Mechanical and Damping Behavior of Age-Hardened and Non-age-hardened Al Alloys After Friction Stir Processing
}

\author{
Hiang-Jie Jiang ${ }^{1} \cdot$ Bing Zhang $^{2} \cdot$ Chong-Yu Liu $^{1} \cdot$ Zhen-Xing Yang ${ }^{1,3} \cdot$ Zong-Yi Ma $^{4}$ \\ Received: 20 October 2018 / Revised: 14 January 2019 / Published online: 26 April 2019 \\ (C) The Chinese Society for Metals (CSM) and Springer-Verlag GmbH Germany, part of Springer Nature 2019
}

\begin{abstract}
This study investigated the microstructure, mechanical, and damping properties of a non-age-hardened $\mathrm{Al}$ alloy (5086) and an age-hardened $\mathrm{Al}$ alloy (7075) after friction stir processing (FSP). Microstructural analyses indicate that FSP led the grain refinement of samples, and the grains size decreased with the decrease in the tool rotation rate. Furthermore, FSP with low rotation rate promotes the $\eta$ phase precipitation in the 7075 alloy, causing the micron-sized particles in the 5086 alloy to break up. After being subjected to FSP with low rotation rate, the 5086 and 7075 alloys exhibited excellent mechanical and damping properties. Such improved properties were ascribed to their equilibrium grain boundaries, fine grain, low density of dislocations, high fraction of high misorientation angle, and uniform particle distribution.
\end{abstract}

Keywords Aluminum alloy $\cdot$ Mechanical properties $\cdot$ Damping

\section{Introduction}

Commercial aluminum (Al) alloys have been widely used in the automotive, aircraft manufacturing, and shipbuilding industries, because of their excellent mechanical properties and low densities [1-4]. Vibrations, which often lead to fatigue failure of structural materials, have been the subject of increasing attention in the above fields [5]. The high damping capacity of materials promotes the mechanical energy absorption and dissipation during vibrations [6-9].

Available online at http://link.springer.com/journal/40195

Chong-Yu Liu

lcy261@glut.edu.cn

$\triangle$ Zong-Yi Ma

zyma@imr.ac.cn

1 College of Material Science and Engineering, Guilin University of Technology, Guilin 541004, China

2 State Key Laboratory of Metastable Materials Science and Technology, Yanshan University, Qinhuangdao 066004, China

3 Alnan Aluminium Co., Ltd., Nanning 530031, China

4 Shenyang National Laboratory for Materials Science, Institute of Metal Research, Chinese Academy of Sciences, Shenyang 110016, China
However, commercial $\mathrm{Al}$ alloy is a low damping material, and its damping capacity needs to be improved to meet the increasing demand for high-damping materials in engineering applications.

In the previous study, it was found that the rolled binary Al-Zn alloy exhibited an excellent damping capacity [8, $10,11]$. The as-deformed $\mathrm{Al}-\mathrm{Zn}$ alloys were always characterized by the structure of wetting $\mathrm{Al} / \mathrm{Zn}$ interface and fine grains, corresponding to the excellent grain boundaries (GBs) sliding during deformation [12]. Thus, the high damping capacity of the binary Al- $\mathrm{Zn}$ alloy can be attributed to its high GBs sliding capacity, according to the interface damping theory [13]. Therefore, optimizing grain structures could improve the GB sliding capacity, which in turn enhances the damping capacity of commercial $\mathrm{Al}$ alloys.

Friction stir processing (FSP) is an effective method to fabricate $\mathrm{Al}$ alloys with ultrafine and equiaxed grains structure. It was found that this structure can promote the GB sliding in Al alloys [14-19], and these FSP samples always exhibit superplasticity [16, 20, 21]. Thus, FSP could be also used to improve the damping capacity of commercial $\mathrm{Al}$ alloys.

Here the effects of FSP on the microstructure, mechanical properties, and damping capacity of both the age-hardened (7075) and non-age-hardened (5086) alloys are investigated. The aim is to fabricate high-performance commercial $\mathrm{Al}$ 
alloys with excellent damping capacity and mechanical properties by means of FSP.

\section{Experimental}

The raw materials were 5086-H112 plate and 7075 plate with solid solution treatment (SS) state. The thickness of the two plates was $10 \mathrm{~mm}$. Table 1 shows the compositions of the 5086 and 7075 alloys. For the 5086 alloy, FSP was performed at a tool traverse speed of $100 \mathrm{~mm} \mathrm{~min}^{-1}$ and rotation rates of 400 and $1200 \mathrm{rpm}$. These samples were defined as 400-100-FSP 5086 and 1200-100-FSP 5086, respectively. For the 7075 alloy, FSP was performed at a tool traverse speed of $50 \mathrm{~mm} \mathrm{~min}^{-1}$ and rotation rates of 400 and $800 \mathrm{rpm}$. These samples were defined as 40050-FSP 7075 and 800-50-FSP 7075, respectively. The tool with a concave shoulder of $10 \mathrm{~mm}$ in diameter and a taper threaded pin of $2.5 \mathrm{~mm}$ in length was used.

Electron backscatter diffraction (EBSD) and transmission electron microscopy (TEM) were employed to examine the microstructures of the samples. The specimens for EBSD were mechanically polished and then electrolytically polished in a solution of $10 \%$ perchloric acid and $90 \%$ alcohol at $20 \mathrm{~V}$ in room temperature. EBSD analysis was performed using a Hitachi S3400N scanning electron microscope coupled with an EDAX EBSD system at an operating voltage of $20 \mathrm{kV}$ and a working distance of $15 \mathrm{~mm}$. The specimens for TEM were polished to a thickness of $50 \mathrm{~mm}$ and then thinned by using a twinjet electropolishing device in a solution of $10 \%$ perchloric acid and $90 \%$ methanol at room temperature. TEM images were obtained by TEM (JEOL-2010) at $200 \mathrm{kV}$. The microstructural examination was performed on the rolling direction-normal direction plane for the base metals (BMs) and FSP direction-normal direction plane for the FSP samples.

The tensile tests were performed on an Instron-3369type testing machine, and the tensile test specimens were parallel to the FSP direction. The thickness of tensile specimen was $3 \mathrm{~mm}$. The damping performance was performed on TA-Q800-type dynamic mechanical analyzer, and specimens for the damping test were machined in the size of $25 \mathrm{~mm} \times 4 \mathrm{~mm} \times 1.2 \mathrm{~mm}$. The damping test was conducted at $1 \times 10^{-4}$ strain amplitude, $1 \mathrm{~Hz}$ frequency, the test temperatures from 50 to $355^{\circ} \mathrm{C}$, and the heating rate of $5{ }^{\circ} \mathrm{C} / \mathrm{min}$.

\section{Results and Discussion}

Figure 1 shows the TEM micrographs of the BMs and FSP samples. The energy-dispersive spectroscopy, which was not displayed in this paper, showed the second-phase particles in the $5086 \mathrm{BM}$ were $\mathrm{Al}_{6} \mathrm{Mn}, \mathrm{Al}_{3} \mathrm{Mg}_{2}$, and $\mathrm{Mn}-\mathrm{Fe}-\mathrm{Al}$ intermetallic phases. Furthermore, the high density of dislocations was also observed in the $5086 \mathrm{BM}$ due to the hot deformation (Fig. 1a). FSP is a severe plastic deformation process, and the FSP with low rotation rate caused the significant breakup of these particles in the 5086 alloy (Fig. 1b). The heat input during FSP increased with increasing the rotation rate [18, 22-24]. Thus, increasing the tool rotation rate enhanced the temperature, thereby dissolving some of $\mathrm{Al}_{3} \mathrm{Mg}_{2}$ phase due to the high solubility of $\mathrm{Mg}$ atoms in the $\mathrm{Al}$ lattice. As a result, the density of second-phase particles in the 1200-100-FSP 5086 decreased (Fig. 1c). The temperature rise during FSP also led to the annihilation of dislocations in the 5086 alloy, and thus, the FSP 5086 samples showed a lower density of dislocations than the BM.

The residual $\mathrm{Zn}_{2} \mathrm{Mg}(\eta)$ phase can be observed in the 7075 SS alloy (Fig. 1d). The 7075 alloy is an age-hardened $\mathrm{Al}$ alloy, and the temperature rise during FSP with low rotation rate caused the precipitation of the $\eta$ phase. A large size and high density of precipitated $\eta$ phase were thus observed in the 400-50-FSP 7075 sample (Fig. 1e). Increasing the rotation rate to $800 \mathrm{rpm}$, the coarsening of the $\eta$ phase in the 7075 alloy was promoted, but the high temperature also led the resolution of some $\eta$ phase, and more solute atoms were retained in the Al lattice. Thus, the 800-50-FSP 7075 exhibited a lower density and larger grain size of precipitated phase than the 400-50-FSP 7075 (Fig. 1f).

Figure 2 shows the grain structures of the BMs and FSP samples. The $5086 \mathrm{BM}$ had a bimodal structure composed of equiaxed recrystallized grains with $2 \mu \mathrm{m}$ in diameter, and elongated coarse grains, which had an average width of $30 \mu \mathrm{m}$ and a length of $80 \mu \mathrm{m}$ (Fig. 2a). FSP promoted the coarsening of fine equiaxed recrystallized grains and the recrystallization of elongated coarse grains in the sample as a result of thermo-mechanical coupling effects. Thus, the uniform distribution of the grain size was observed in the 5086 after FSP, and the grains in shape of the FSP samples were equiaxed (Fig. 2b, c). The 7075 BM possessed coarse equiaxed grains due to the solid solution treatment, and most of the grains in the sample were larger than $100 \mu \mathrm{m}$ (Fig. 2d). The equiaxed recrystallized grains were also found in the two FSP 7075 samples (Fig. 2e, f).
Table 1 Chemical compositions of the 5086 and 7075 alloys

\begin{tabular}{llllllll}
\hline Alloys & $\mathrm{Zn}$ & $\mathrm{Mg}$ & $\mathrm{Cu}$ & $\mathrm{Fe}$ & $\mathrm{Mn}$ & $\mathrm{Si}$ & $\mathrm{Cr}$ \\
\hline 5086 & 0.03 & 4.1 & 0.02 & 0.16 & 0.45 & 0.07 & 0.1 \\
7075 & 5.5 & 2.4 & 1.5 & 0.13 & 0.03 & 0.06 & 0.2 \\
\hline
\end{tabular}



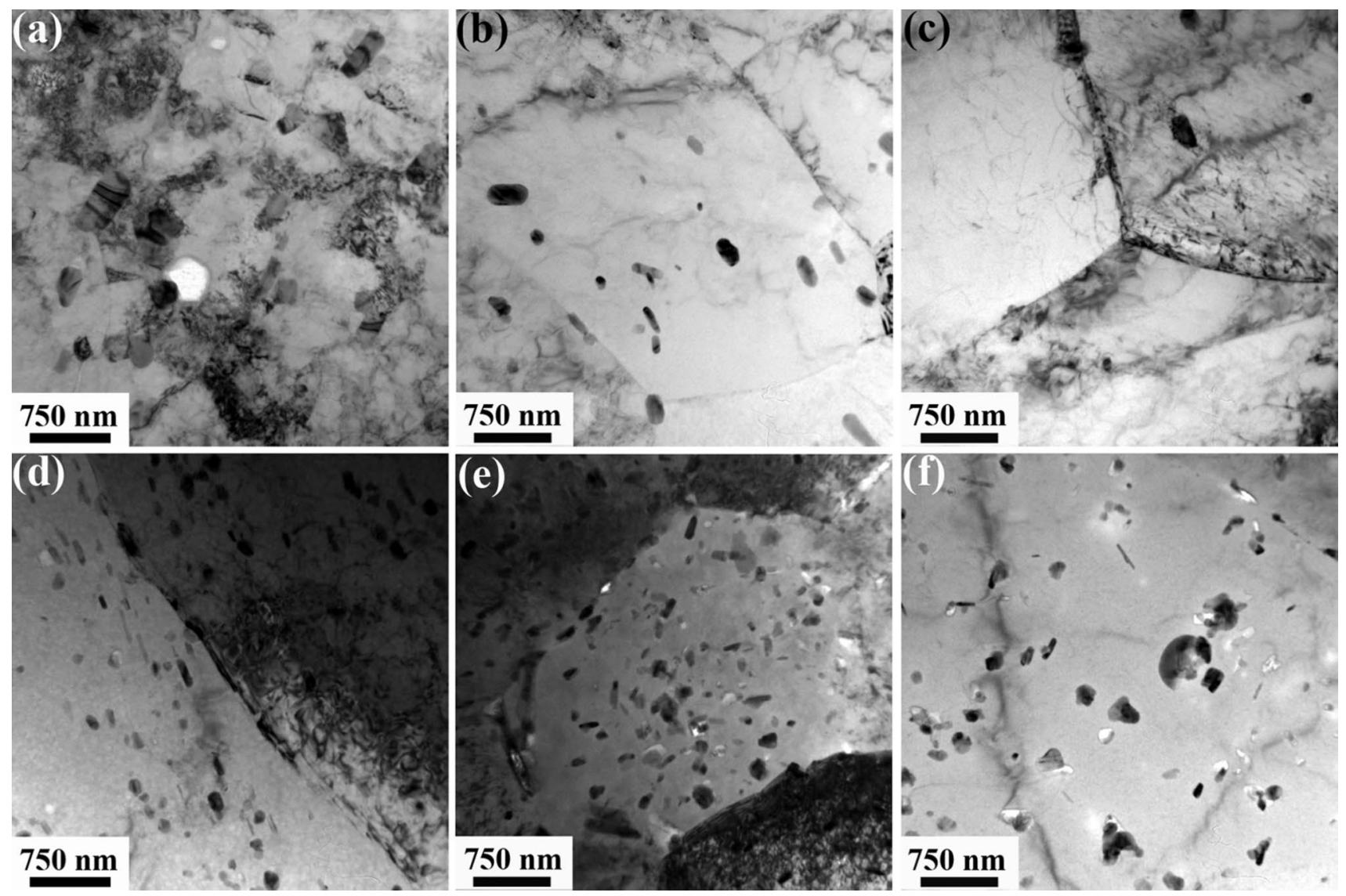

Fig. 1 TEM micrographs of a 5086 BM, b 400-100-FSP 5086, c 1200-100-FSP 5086, d 7075 BM, e 400-50-FSP 7075, f 800-50-FSP 7075 samples

Figure 3 shows the grain size distributions of the FSP samples. For the same alloy, the FSP sample with high rotation rate exhibited higher frequency of large grains than the sample after low rotation rate FSP. The average grain size of the 400-100-FSP 5086 sample was $\sim 8.2 \mu \mathrm{m}$ (Fig. 3a), and the 1200-100-FSP 5086 sample exhibited a larger average grain size of $\sim 10.5 \mu \mathrm{m}$ (Fig. 3b). Compared with the FSP 5086 samples, the FSP 7075 samples exhibited narrower grain size distribution. The average grain sizes of the 400-50-FSP 7075 and 800-50-FSP 7075 samples were $\sim 4$ (Fig. 3c) and $\sim 6 \mu \mathrm{m}$ (Fig. 3d), respectively.

The coarsening of recrystallization grain in the $\mathrm{Al}$ alloys during FSP can be effectively inhibited by reducing the rotation rate. Therefore, the FSP sample with low rotation rate exhibited a smaller grain size than the FSP sample with high rotation rate for the same alloy. The heat input during FSP also decreased with increasing the tool traverse speed [18]. However, the average grain size of the 400-50-FSP 7075 was much lower than that of 400100-FSP 5086 sample; even the 7075 BM exhibited larger grains than the 5086 BM (Fig. 2a, d). The 7075 alloy content much more fine particle phases (Fig. 1), which can pin the GBs during thermo-mechanical treatments, than the 5086 alloy. Thus, the coarsening of recrystallization grain in the 7075 was effectively inhibited during FSP.

Figure 4 shows the misorientation angle distributions of 5086 and 7075 samples. The two BMs exhibited higher fraction of low angle boundaries than the FSP samples. The average angles of the 400-100-FSP 5086, 1200-100FSP 5086, 400-50-FSP 7075, and 800-50-FSP 7075 samples were $24.5^{\circ}, 21.3^{\circ}, 32.1^{\circ}$, and $25.1^{\circ}$, respectively.

Figure 5 depicts the stress-strain curves and mechanical properties of the samples, respectively. Compared with the $5086 \mathrm{BM}$, the FSP 5086 samples exhibited lower yield strength (YS), greater elongation (EL), and nearly equal ultimate tensile strength (UTS). Compared with the microstructure of BM, the FSP samples were characterized by lower density of dislocations (Fig. 1) and finer grains (Figs. 2, 3). Thus, the FSP samples exhibited higher GB strengthening but lower dislocations strengthening than the $\mathrm{BM}$. For the $\mathrm{Al}$ alloys, the GB strengthening effect is not obvious due to their low Hall-Petch parameter. Thus, FSP decreased the YS of 5086 alloy. 

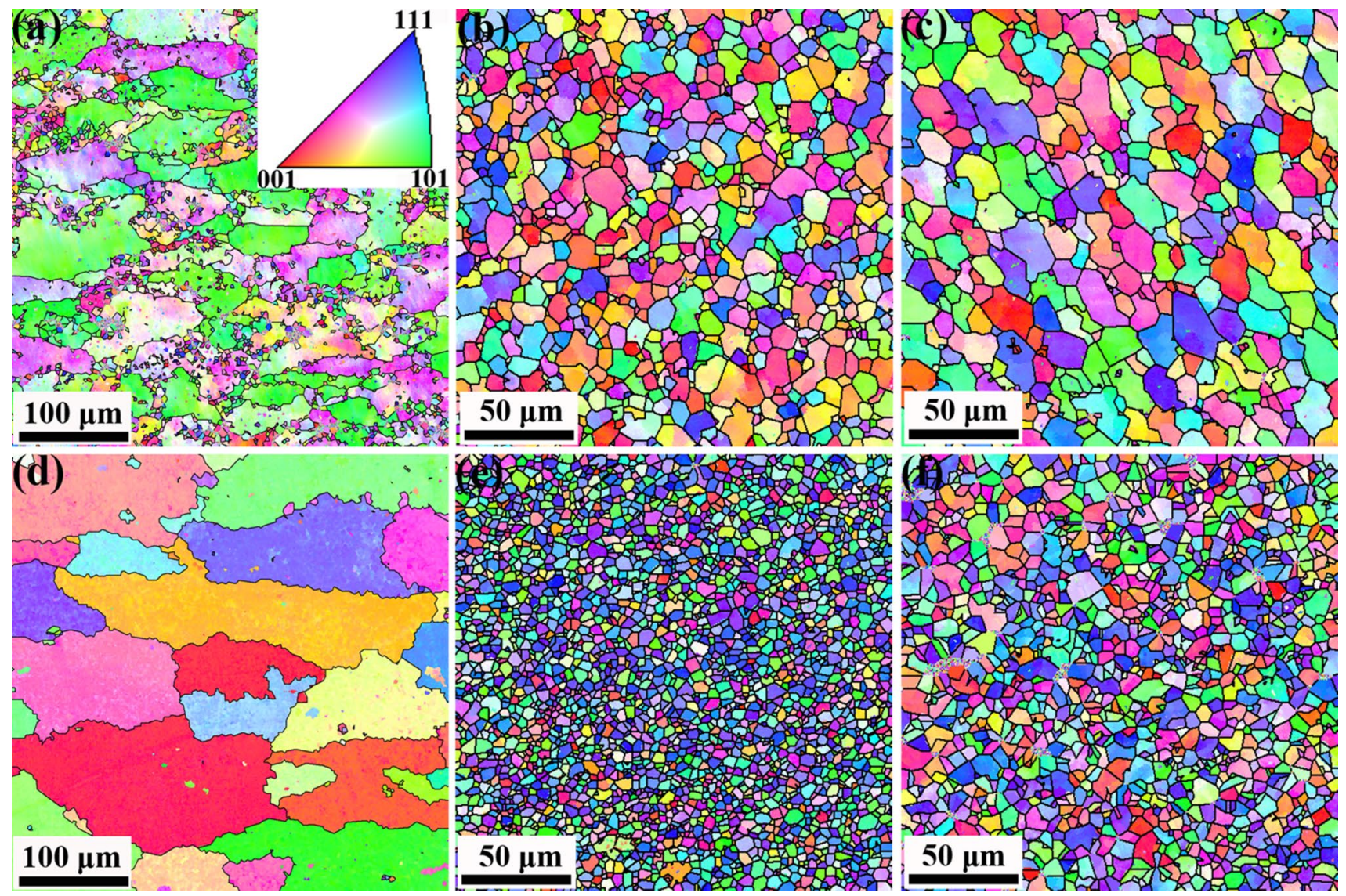

Fig. 2 Orientation maps of a 5086 BM, b 400-100-FSP 5086, c 1200-100-FSP 5086, d 7075 BM, e 400-50-FSP 7075, f 800-50-FSP 7075 samples

The FSP 5086 samples displayed greater EL than the 5086 BM mainly due to their higher work hardening capabilities. The FSP samples possessed low dislocations density, equilibrium GBs, and more uniform distribution of second phase, thereby leading to excellent dislocation accumulation capability during tension, which, in turn, improved the work hardening capability, and the high work hardening rate always corresponds to high $\mathrm{EL}$ of $\mathrm{Al}$ alloys [25, 26].

Compared with the 1200-100-FSP 5086 sample, the 300100-FSP 5086 sample exhibited finer grains (Fig. 3) and higher fraction of high angle GB (Fig. 4). The finer and more homogeneous grains could prevent the strain localization by redistribute stress in the samples during deformation process [27], Thus, the 400-100-FSP 5086 sample had higher UTS and EL than the 1200-100-FSP 5086 sample (Fig. 5a).

The FSP 7075 samples had lower strengths than the 7075 BM samples. The ductility of the FSP 7075 was improved by decreasing the tool rotation rate, and the 400-50-FSP 7075 sample achieved an EL of up to $15 \%$, which is equal to that of the BM (Fig. 5b). Microstructural analysis revealed that FSP has two competing effects on the tensile strength of the 7075 SS: (1) the decrease in size of grains (Figs. 2, 3) and the increase in density of micronsized particles (Fig. 1) increased the GB and second-phase strengthening effects of the sample, respectively; and (2) the solid solution decomposition (Fig. 1) decreased the solid solution strengthening effect of the sample. The net effect led the FSP samples exhibit lower strength than the $\mathrm{BM}$. More solute atoms were retained in the $\mathrm{Al}$ lattice in the 800-50-FSP 7075 sample (Fig. 1); thus, this sample had a higher strength than the 400-50-FSP 7075 sample due to the higher solid solution strengthening. The finer and more homogeneous grains (Figs. 2, 3, 4) led the 40050-FSP 7075 sample to have higher EL than the 800-50FSP 7075 sample (Fig. 5b).

Figure 6 shows the variations in damping capacity with temperature of samples. As the temperature increased, the damping capacities of all samples improved. For the 5086 alloy, 400-100-FSP improved the damping capacity, whereas 1200-100-FSP deteriorated the damping capacity. FSP with both low and high tool rotation rates improved the damping property of the 7075 alloy.

According to the current damping theory, interface and dislocation damping are the two important damping 

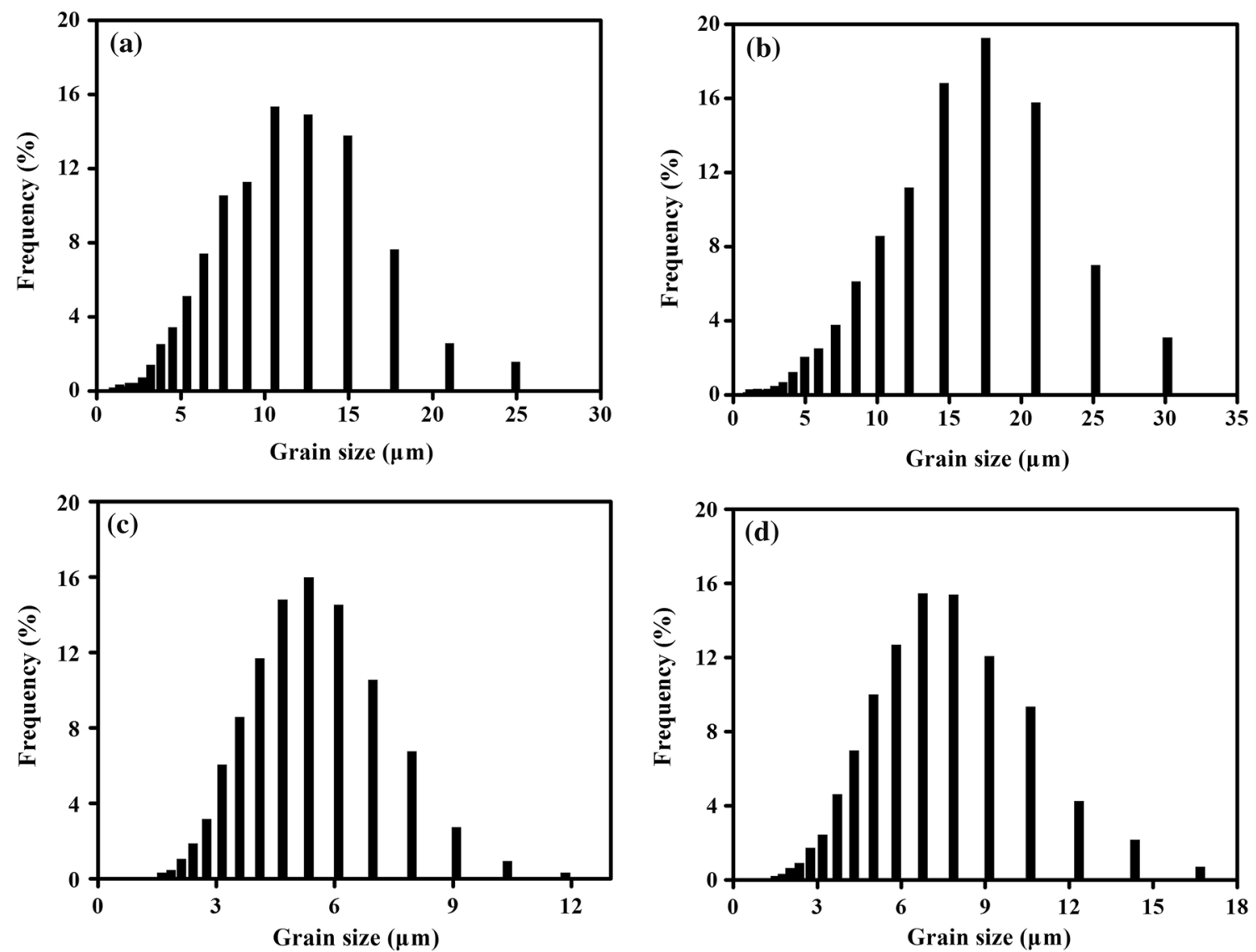

Fig. 3 Grain size distributions for a 400-100-FSP 5086, b 1200-100-FSP 5086, c 400-50-FSP 7075, d 800-50-FSP 7075 samples

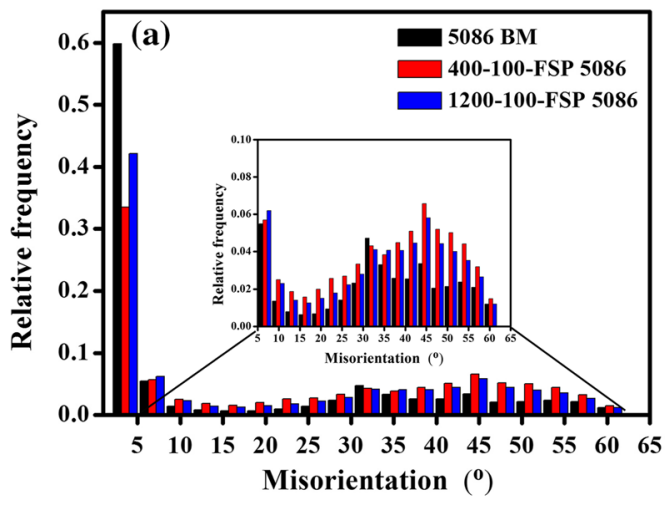

Fig. 4 Misorientation angle distributions of a 5086, b 7075 alloys

mechanisms for metals during vibration at high temperatures [28]. The damping peaks, which correspond to the GB relaxation of $\mathrm{Al}$ during the temperature-dependent damping test $[29,30]$, were obtained in the curves for the four FSP samples. This means that the FSP promoted the GBs sliding of $\mathrm{Al}$ alloys, and the GBs sliding led the mechanical energy to convert into thermal energy, and then, the interface damping was increased during vibration $[31,32]$.

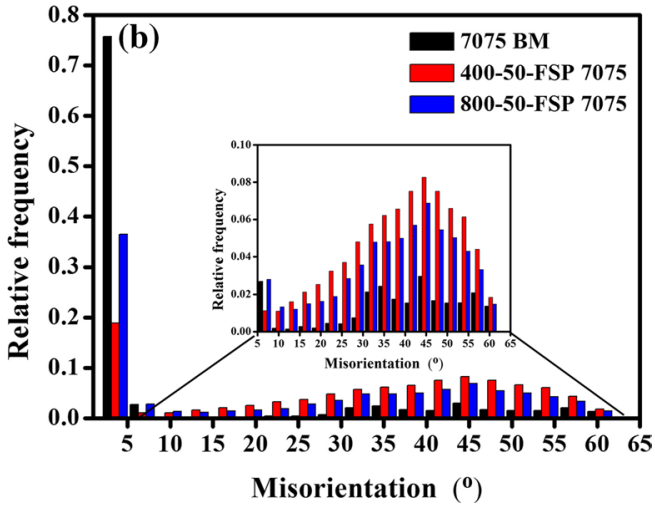

The damping peak was observed at approximately $260{ }^{\circ} \mathrm{C}$ in the curves for the FSP 5086 samples, while the peak was observed at approximately $230{ }^{\circ} \mathrm{C}$ in the curves for the FSP 7075 samples. Grain refinement can reduce the temperature of GB sliding in the Al alloys with high fraction of high misorientation angle structure, thereby reducing their GB sliding temperatures [33]. The FSP 7075 alloys with finer grains thus exhibited lower damping peak temperatures and 

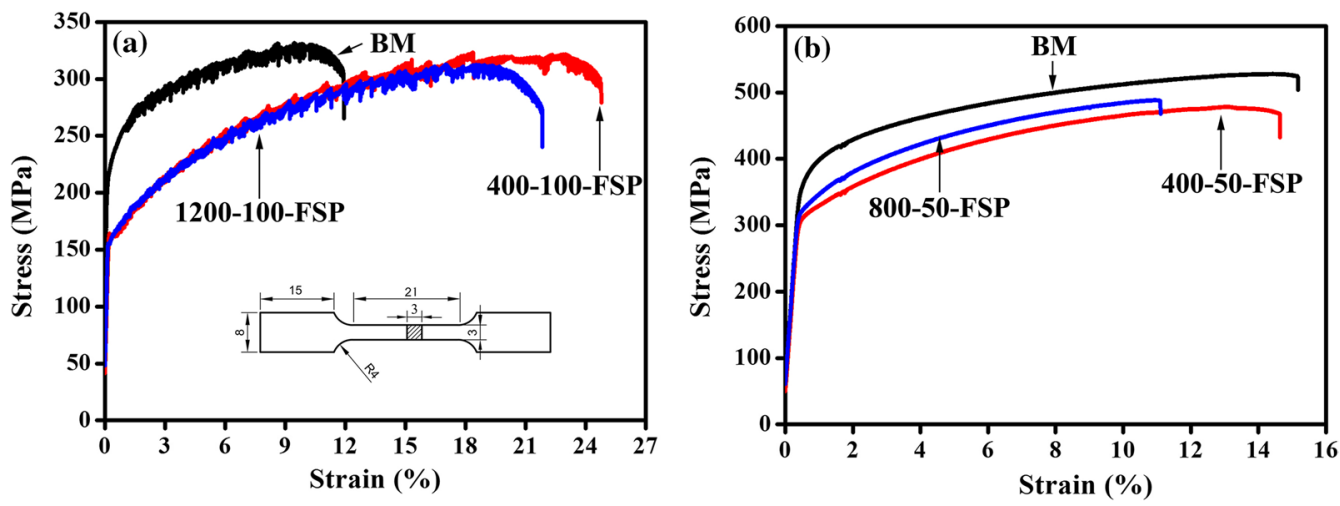

Fig. 5 Stress-strain curves of a 5086, b 7075 alloys
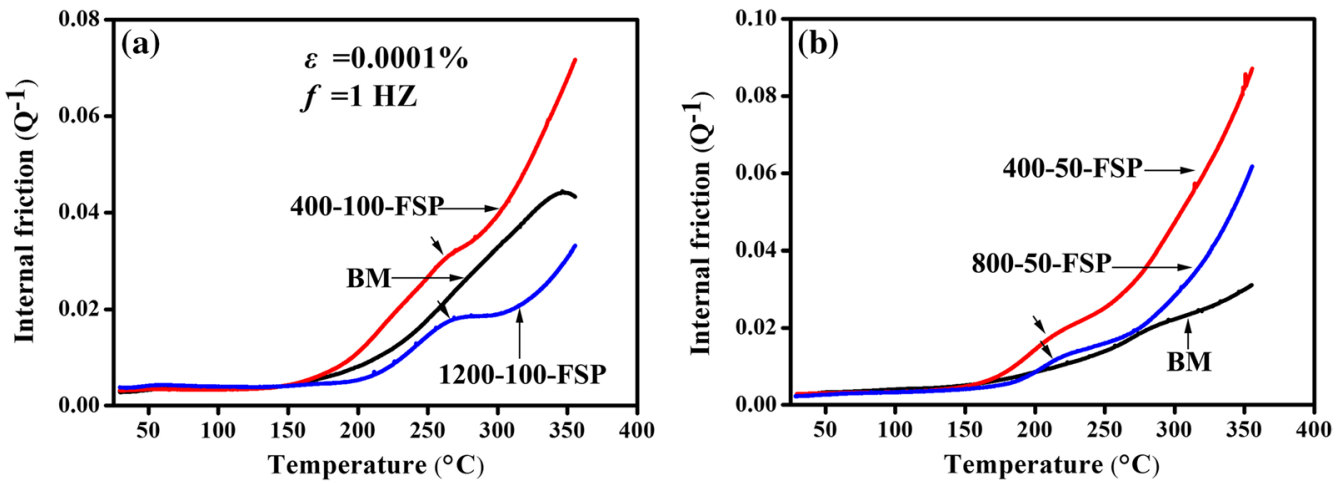

Fig. 6 Damping capacities of a 5086, b 7075 alloys

higher internal friction value than the FSP 5086 alloys. For the same alloy, the finer grains (Fig. 3) and higher fraction of high angle boundaries (Fig. 4) also led the FSP sample with low rotation rate exhibit higher internal friction value than the FSP sample with high rotation rate and BM.

The number of point defects increases with the increase in temperature during vibration, and the damping behavior of metal is controlled by vacancy motion $[34,35]$. Thus, the dislocation damping also increased with the increase in the temperature.

According to the dislocation damping mechanism, the second phase could act as the pinning points, which pin the motion of vacancies during vibration and reduce the internal friction of metals. For the 5086 alloy, the FSP samples exhibited higher density of second phase than the BM due to the particle fragmentation during FSP. While for the 7075 alloy, the FSP samples also exhibited higher density of precipitated particles than the BM due to the precipitation during FSP (Fig. 1). Thus, the FSP decreased the dislocation damping during vibration. The net effects of interface and dislocation damping behavior led the 1200-100-FSP 5086 exhibit lower internal friction than the 5086 BM (Fig. 6a).

\section{Conclusions}

The effect of FSP on the microstructure, mechanical, and damping properties of 5086 and 7075 alloys were studied in this paper. The following conclusions were obtained:

(1) FSP caused the breakup of micron-sized particles in the 5086 matrix and promoted the precipitation in the 7075 alloy. Low rotation rate inhibited the coarsening of the recrystallized grains in the 5086 and 7075 alloys during FSP. Average grain sizes of $\sim 8.2$ and $\sim 4 \mu \mathrm{m}$ were obtained in the 400-100-FSP 5086 and 400-50FSP 7075 samples, respectively. FSP also enhanced the fraction of high angle boundaries.

(2) Compared with the 5086 H112 alloy, the 5086 after FSP exhibited lower YS, greater EL, and nearly equal ultimate UTS, while the mechanical properties of 7075 SS alloy were deteriorated by FSP.

(3) FSP promoted the GBs sliding of 5086 and 7075 alloys and then increased the interface damping, while the FSP also increased the density of the second phases in the 5086 and 7075 alloys and then decreased the 
dislocation damping during vibration. The net effects led the FSP sample with low rotation rate exhibit higher internal friction value than the FSP sample with high rotation rate and $\mathrm{BM}$ for the same alloy.

Acknowledgements This work was financially supported by the National Natural Science Foundation of China (No. 51601045), the Guangxi Natural Science Foundation (No. 2016GXNSFDA380028) and the Science and Technology Major Project of Guangxi (No. GKAA17202007).

\section{References}

[1] S.G. Benoit, V.B. Chalivenra, M.A. Rice, R.F. Doleski, Metall. Mater. Trans. A 47, 4476 (2016)

[2] D. Wang, D.R. Ni, Z.Y. Ma, Mater. Sci. Eng. A 494, 360 (2008)

[3] J. Esquivel, R.K. Gupta, Acta Metall. Sin. (Engl. Lett.) 30, 333 (2017)

[4] G.B. Teng, C.Y. Liu, Z.Y. Ma, W.B. Zhou, L.L. Wei, Y. Chen, J. Li, Y.F. Mo, Mater. Sci. Eng. A 713, 61 (2018)

[5] G. Liu, S.W. Tang, J. Hu, L.C. Kong, Mater. Sci. Eng. A 624, 118 (2015)

[6] D.R. Ni, Z.Y. Ma, Acta Metall. Sin. (Engl. Lett.) 27, 739 (2014)

[7] J. Göken, J. Swiostek, H. Hurdelbrink, U. Keil, Acta Metall. Sin. (Engl. Lett.) 26, 113 (2013)

[8] Z.H. Ma, F.S. Han, J.N. Wei, J.C. Gao, Metall. Mater. Trans. A 32, 2657 (2000)

[9] D.R. Ni, J.J. Wang, Z.Y. Ma, J. Mater. Sci. Technol. 32, 162 (2016)

[10] H.J. Jiang, C.Y. Liu, Z.Y. Ma, X. Zhang, L. Yu, M.Z. Ma, R.P. Liu, J. Alloys Compd. 722, 138 (2017)

[11] H.J. Jiang, C.Y. Liu, Y. Chen, Z.X. Yang, H.F. Huang, L.L. Wei, Y.B. Li, H.Q. Qi, J. Alloys Compd. 739, 114 (2018)

[12] R.Z. Valiev, M.Y. Murashkin, A. Kilmametov, B. Straumal, N.Q. Chinh, T.G. Langdon, J. Mater. Sci. 45, 4718 (2010)

[13] J. Zhang, R.J. Perez, E.J. Lavernia, J. Mater. Sci. 28, 2395 (1993)
[14] K. Zhao, Z.Y. Liu, B.L. Xiao, D.R. Ni, Z.Y. Ma, Acta Metall. Sin. (Engl. Lett.) 31, 134 (2018)

[15] F.C. Liu, Z.Y. Ma, F.C. Zhang, J. Mater. Sci. Technol. 28, 1025 (2012)

[16] I. Charit, R.S. Mishra, J. Mater. Sci. Technol. 34, 214 (2018)

[17] M.A. García-Bernal, R.S. Mishra, R. Verma, D. Hernández-Silva, Mater. Sci. Eng. A 670, 9 (2016)

[18] Z.Y. Ma, Metall. Mater. Trans. A 39, 642 (2008)

[19] J.G. Ren, L. Wang, D.K. Xu, L.Y. Xie, Z.C. Zhang, Acta Metall. Sin. (Engl. Lett.) 30, 228 (2017)

[20] V.V. Patel, V. Badheka, A. Kumar, Mater. Manuf. Process. 31, $1573(2016)$

[21] V.V. Patel, V. Badheka, A. Kumar, J. Mater. Process. Technol. 240, 68 (2017)

[22] P. Xue, Z.Y. Huang, B.B. Wang, Y.Z. Tian, W.G. Wang, B.L. Xiao, Z.Y. Ma, Sci. China Mater. 59, 531 (2016)

[23] C.Y. Liu, B. Qu, P. Xue, Z.Y. Ma, K. Luo, M.Z. Ma, R.P. Liu, J. Mater. Sci. Technol. 34, 112 (2018)

[24] B.B. Wang, F.F. Chen, F. Liu, W.G. Wang, P. Xue, Z.Y. Ma, J. Mater. Sci. Technol. 33, 1009 (2017)

[25] Y.H. Zhao, X.Z. Liao, S. Cheng, E. Ma, Y.T. Zhu, Adv. Mater. 18, $2280(2006)$

[26] Y.T. Zhu, X.Z. Liao, Nat. Mater. 3, 351 (2004)

[27] D. Yadav, R. Bauri, Mater. Sci. Eng. A 539, 85 (2012)

[28] S.Q. Chen, X.P. Dong, R. Ma, L. Zhang, H. Wang, Z.T. Fan, Mater. Sci. Eng. A 551, 87 (2012)

[29] B. Cai, Q.P. Kong, P. Cui, H.T. Cong, X.K. Sun, Scr. Mater. 44, $1043(2001)$

[30] Z.Q. Yang, J. Chen, L.L. He, H.T. Cong, H.Q. Ye, Acta Mater. 57, 3633 (2009)

[31] H. Watanabe, T. Mukai, M. Sugioka, K. Ishikawa, Scr. Mater. 51, 291 (2004)

[32] J. Zhang, R.J. Perez, E.J. Lavernia, J. Mater. Sci. 28, 2395 (1993)

[33] F.C. Liu, Z.Y. Ma, L.Q. Chen, Scr. Mater. 60, 968 (2009)

[34] M. Yamaguchi, J. Bernhardt, K. Faerstein, D. Shtansky, Y. Bando, I.S. Golovin, H.R. Sinning, D. Golberg, Acta Mater. 61, 7604 (2013)

[35] A.V. Mikhaylovskaya, V.K. Portnoy, A.G. Mochugovskiy, MYu. Zadorozhnyy, NYu. Tabachkova, I.S. Golovin, Mater. Des. 109, 197 (2016) 